\title{
Haemodynamic effects of intravenous amrinone in patients with impaired left ventricular function
}

\author{
P T WILMSHURST, D S THOMPSON, B S JENKINS, D J COLTART, M M WEBB-PEPLOE
}

From the Department of Cardiology, St Thomas's Hospital, London

SUMMARY The effects of intravenous amrinone on resting haemodynamic function were investigated in 15 patients with impaired left ventricular function. All patients received $1.5 \mathrm{mg} / \mathrm{kg}$ and 10 received a further $2 \mathrm{mg} / \mathrm{kg}$. We observed dose related increases in heart rate and cardiac index, and reductions in mean arterial pressure, left ventricular end-diastolic pressure, and systemic vascular resistance. A small reduction in left ventricular end-diastolic volume and a $36 \%$ increase in ejection fraction occurred. No significant change in $\max \mathrm{dp} / \mathrm{dt}, \min \mathrm{dp} / \mathrm{dt},\left(\frac{\mathrm{Max} \mathrm{dp} / \mathrm{dt}}{\mathrm{P}}\right), \max \left(\frac{\mathrm{dp} / \mathrm{dt}}{\mathrm{P}}\right), \mathrm{KVmax}$ or the ratio of left ventricular end-systolic pressure to left ventricular end-systolic volume was detected. It is concluded that the beneficial effects of intravenous amrinone on the resting haemodynamics in our patients were attributable to vasodilatation, with the drug having no demonstrable positive inotropic effect.

Considerable interest has been aroused by amrinone, a new bipyridine derivative which, in a variety of in vitro and in vivo animal preparations, has been shown to have positive inotropic properties, unrelated to sympathomimetic or cardiac glycoside activity. ${ }^{1}$ It has also been shown to have direct vasodilator properties in animals. ${ }^{2} \mathrm{~A}$ beneficial increase in cardiac index and a reduction in filling pressures with this drug in patients with cardiac failure are well described. ${ }^{3-5}$ It is unclear how much these benefits are the result of a positive inotropic effect and how much the result of vasodilatation.

We therefore investigated the effect of intravenous amrinone on basic haemodynamic function as well as a number of indices of left ventricular contractility of proven value in the assessment of inotropic function. These included $\max d p / d t,{ }^{6} \max d p / d t$ divided by simultaneous developed pressure $\left(\frac{\max \mathrm{dp} / \mathrm{dt}}{\mathrm{P}}\right)$, the peak measured shortening velocity of the contractile element $\left(\max \left(\frac{\mathrm{dp} / \mathrm{dt}}{\mathrm{P}}\right)\right),{ }^{8}$ the product of the series elastic stiffness constant $(K)$ and the velocity of contractile shortening at zero load (KVmax), 9 and the ratio of left ventricular end-systolic pressure to left ventricular end-systolic volume (LVESP/LVESV). 10

Accepted for publication 24 August 1982

\section{Patients and methods}

Fifteen patients with impaired left ventricular function, whose clinical details appear in Table 1, were studied. (The patients were not investigated in the same order in which they appear in this Table.) Three patients had normal left ventricular end-diastolic volumes, but were included because each had a history of pulmonary oedema, had impaired exercise performance despite treatment, and had reductions in all indices of left ventricular contractility. The patients'

Table 1 Clinical characteristics of patients studied

\begin{tabular}{cccll}
\hline Case No. $\begin{array}{c}\text { Age } \\
(y)\end{array}$ & Sex & Diagnosis & $\begin{array}{l}\text { NYHA } \\
\text { grade }\end{array}$ \\
\hline 1 & 19 & F & Idiopathic dilated cardiomyopathy & 3 \\
2 & 45 & F & Idiopathic dilated cardiomyopathy & 2 \\
3 & 59 & M & Idiopathic dilated cardiomyopathy & 3 \\
4 & 41 & M & Idiopathic dilated cardiomyopathy & 2 \\
5 & 30 & M & Idiopathic dilated cardiomyopathy & 3 \\
6 & 36 & M & Idiopathic dilated cardiomyopathy & 2 \\
7 & 39 & M & Idiopathic dilated cardiomyopathy & 3 \\
8 & 37 & M & Idiopathic dilated cardiomyopathy & 3 \\
9 & 41 & M & Idiopathic dilated cardiomyopathy & 2 \\
10 & 53 & M & Coronary artery disease & 3 \\
11 & 51 & M & Coronary artery disease & 4 \\
12 & 51 & M & Coronary artery disease & 3 \\
13 & 45 & M & Coronary artery disease & 3 \\
14 & 43 & F & Hypertensive heart disease & 2 \\
15 & 49 & M & Restrictive cardiomyopathy amyloidosis & 3 \\
\hline
\end{tabular}


routine treatment was continued until the evening before the investigation. Each was receiving diuretics, nine had digoxin, five had vasodilators, three had warfarin, and one had mexilitine. Two patients with dilated cardiomyopathy were receiving prednisolone. Informed written consent was obtained from each patient before the study, which had the approval of the hospital ethical committee.

After an overnight fast and premedication with atropine $(0.6 \mathrm{mg})$ and diazepam $(10 \mathrm{mg})$ right and left heart pressures were measured and coronary arteriography was performed via the right femoral vein and artery. A Gaeltec catheter tip micromanometer (Gaeltec Ltd, Isle of Skye, Scotland) was positioned in the left ventricle via the interatrial septum by a long sheath technique." It was used for recording high fidelity left ventricular pressure, injection of radioopaque contrast ( $76 \%$ Urografin) for single plane (right anterior oblique) left ventricular cineangiography, and injection of indocyanine green dye for measurement of cardiac output. The passage of green dye was detected using a number 5FG Schwarzer fibreoptic catheter connected to an IVH 3 in vivo haemoreflector meter. The Schwarzer catheter was positioned in the aortic arch via a number $8 \mathrm{FG}$ long arterial sheath, the coaxial lumen of which was used to record aortic pressure. In two patients (cases 6 and 7) an electromagnetic flow probe (Carolina Medical Electronics) was used to record flow in the aortic root instead of green dye cardiac outputs. In these two patients aortic pressure was not recorded. Pressures were measured with reference to the sternal angle as zero. Max dp/dt, $\min$ $\mathrm{dp} / \mathrm{dt}$ (peak negative $\mathrm{dp} / \mathrm{dt}$ ), $\left(\frac{\max \mathrm{dp} / \mathrm{dt}}{\mathrm{P}}\right), \max$ $\left(\frac{\mathrm{dp} / \mathrm{dt}}{\mathrm{P}}\right)$, and KVmax were derived by online computer processing of the left ventricular pressure signal.

Measurements of heart rate, cardiac output, and left ventricular and aortic pressures were made in the control state and seven minutes after $1.5 \mathrm{mg} / \mathrm{kg}$ intravenous amrinone. Ten patients received a second dose of $2.0 \mathrm{mg} / \mathrm{kg}$ intravenous amrinone 15 minutes after the first dose. Left ventricular cineangiography was performed in the control state and after the highest dose of amrinone in each subject, allowing 20 minutes to elapse between cineangiography and subsequent measurements. Left ventricular end-diastolic volume

Table 2 Effect of $1.5 \mathrm{mg} / \mathrm{kg}$ and $3.5 \mathrm{mg} / \mathrm{kg}$ intravenous amrinone on basic haemodynamics in patients with impaired left ventricular function

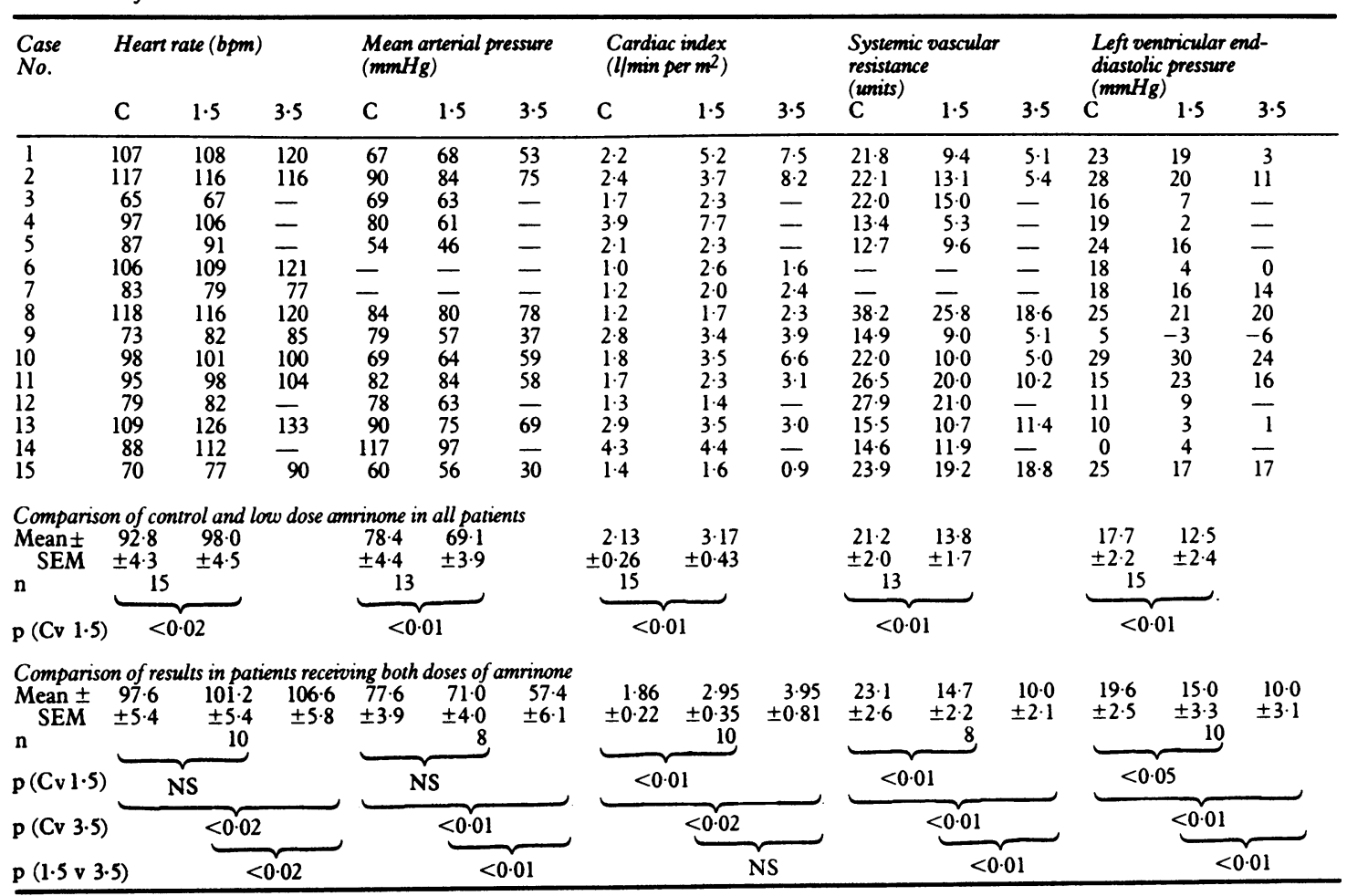


Table 3 Effect of intravenous amrinone on left ventricular volumes in patients with impaired left ventricular function

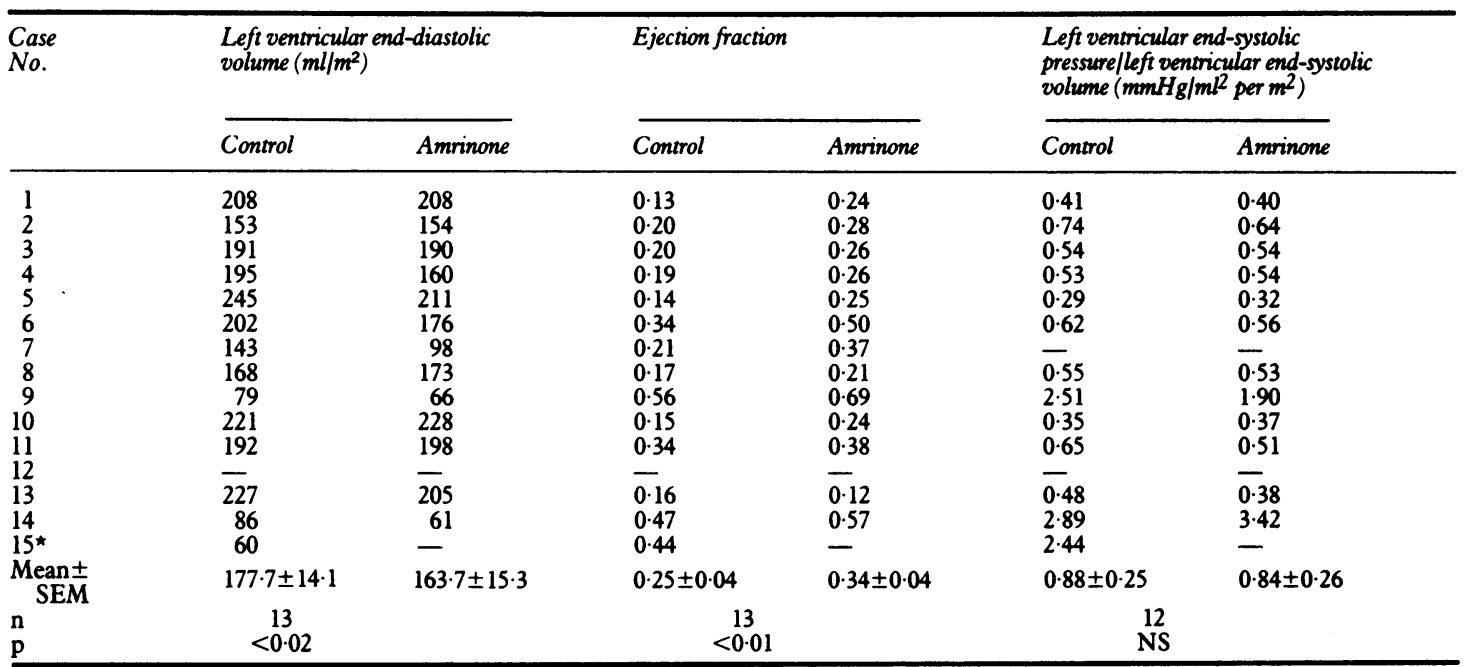

$\star$ Excluded from calculations.

Table 4 Effect of $1.5 \mathrm{mg} / \mathrm{kg}$ and $3.5 \mathrm{mg} / \mathrm{kg}$ intravenous amrinone on indices of contractility derived from left ventricular pressure and min $d p / d t$ in patients with impaired left ventricular function

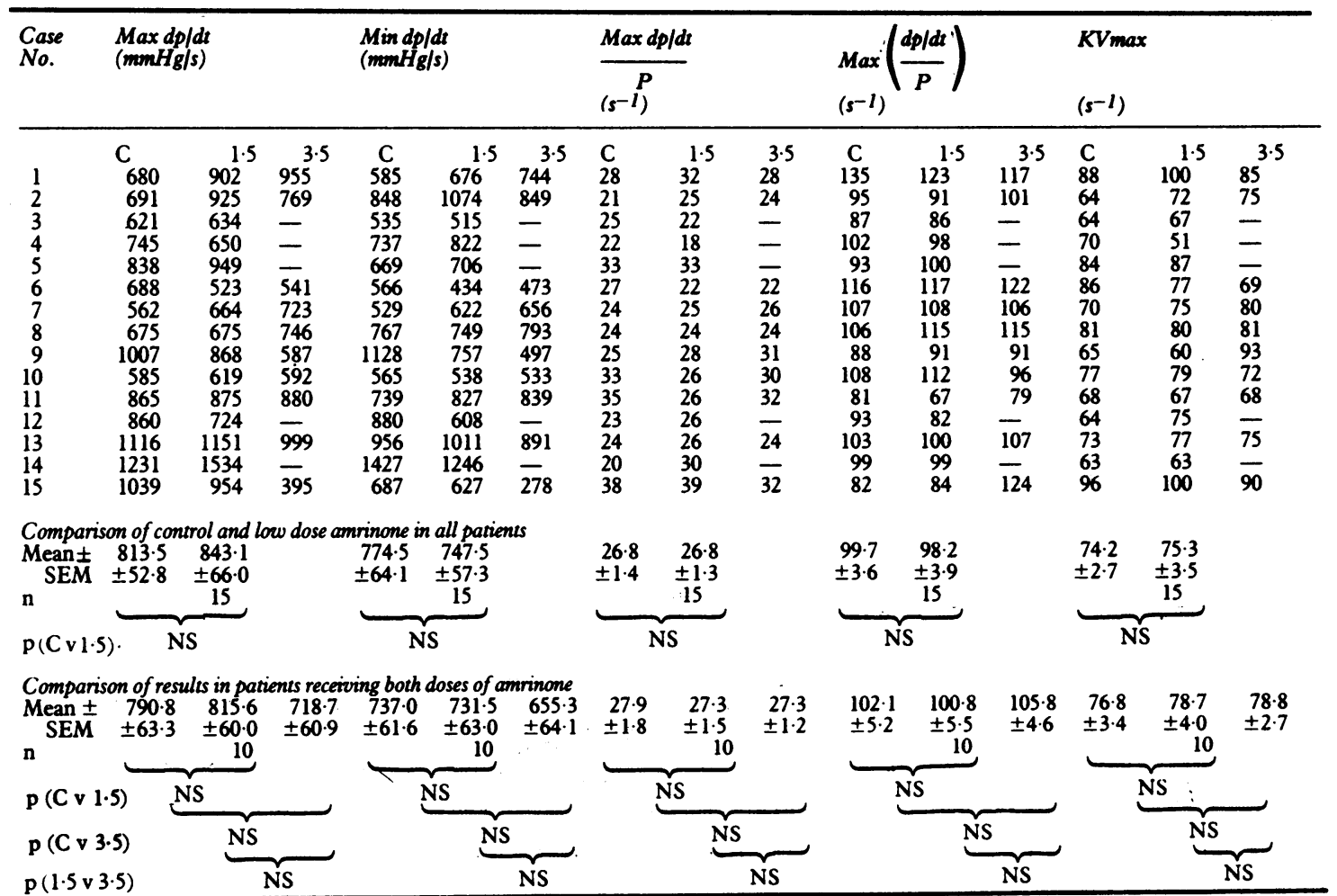


(LVEDV) and end-systolic volume (LVESV) were calculated 12 and normalised for surface area. Total systemic vascular resistance (SVR) was calculated assuming a right atrial pressure of zero to avoid inserting a further catheter. Comparisons between the three states were made using a paired $t$ test. A value of $\mathrm{p}<0.05$ was taken as statistically significant.

\section{Results}

Heart rate rose slightly but significantly, and mean arterial pressure, systemic vascular resistance, and left ventricular end-diastolic pressure (LVEDP) fell appreciably $(\mathrm{p}<0.01)$ on successive doses of amrinone (Table 2). In the two patients whose aortic pressures were not measured, left ventricular systolic pressure fell in one from $82 \mathrm{mmHg}$ in the control state, to 71 $\mathrm{mmHg}$ after $1.5 \mathrm{mg} / \mathrm{kg}$ amrinone and to $49 \mathrm{mmHg}$ after $3.5 \mathrm{mg} / \mathrm{kg}$ amrinone, and was unaltered in the other. Cardiac index also rose considerably on successive doses of the drug; but the difference between the two doses was not significant because in two subjects (cases 6 and 15), one of whom had a restrictive cardiomyopathy because of amyloid heart disease, a large reduction in cardiac index on the higher dose of amrinone occurred. These two patients were studied early in the series and it was recognition of this possibility which prevented administration of the higher dose of amrinone to five of the patients. In the patient with amyloid heart disease administration of the second dose of amrinone was accompanied by severe hypotension requiring intravenous plasma, so that a left ventricular cineangiogram after amrinone was not obtained. In one other patient (case 12) the left ventricular cineangiograms were of inadequate quality to allow volume analysis, and in an additional patient (case 7) the pressure signal was inadequate for calculation of left ventricular end-systolic pressure (LVESP), though volume analysis could be performed. Where two left ventricular cineangiograms were performed left ventricular end-diastolic volume fell and ejection fraction rose after amrinone, but LVESP/LVESV was unaltered (Table 3).

All indices of contractility derived from left ventricular pressure as well as $\mathrm{min} \mathrm{dp} / \mathrm{dt}$ were unaltered by either dose of amrinone (Table 4). Only two subjects (cases 5 and 14) showed a consistent improvement in all indices of left ventricular contractility measured. But both showed less than a $10 \%$ increase in cardiac output, and small reductions in mean arterial pressure and left ventricular end-diastolic pressure on the drug. No clear relation existed between changes in indices of contractility and changes in cardiac index in the same individual.

\section{Discussion}

In patients with congestive cardiac failure reduction in afterload by vasodilating drugs causes an initial increase in cardiac output with little or no fall in blood pressure or rise in heart rate. As higher doses are administered a reflex tachycardia accompanies a fall in blood pressure, which is, at least in part, caused by a decrease in cardiac output as a result of an excessive reduction in preload (as predicted by Starling's law). The initial increase in cardiac output without alteration in heart rate is accomplished by an increase in stroke volume and ejection fraction from a reduced left ventricular end-diastolic volume. It follows that any index of contractility which is affected by changes in heart rate, preload, and afterload will be far from ideal for assessing the inotropic effect of an intervention when there is concomitant vasodilatation. Max dp/dt is increased by increasing heart rate, preload, and afterload. ${ }^{13}$ Changes in heart rate are quantitatively the most important. ${ }^{814}$ Dispute exists with regard to the practical as opposed to theoretical effects of preload and afterload on $\max \mathrm{dp} / \mathrm{dt} .^{8}$

In both the previously published studies 35 in which the effect of amrinone on left ventricular contractility in man were investigated the only index of contractility used was max $\mathrm{dp} / \mathrm{dt}$. Benotti et al. ${ }^{3}$ investigated the effect of intravenous amrinone in eight patients with congestive heart failure. Patients received a variable total dose $(1.85$ to $3.5 \mathrm{mg} / \mathrm{kg})$ in $0.5 \mathrm{mg} / \mathrm{kg}$ increments. The authors compared the haemodynamics seven minutes after the highest dose of amrinone with those before amrinone. They found a significant increase in cardiac index and significant reductions in left ventricular filling pressures, with an increase in max $\mathrm{dp} / \mathrm{dt}$ in the six patients in which it was measured. In two patients max dp/dt was not measured and in both heart rate fell. In the whole group of eight patients heart rate did not change significantly. In the group of six patients, however, in whom $\max \mathrm{dp} / \mathrm{dt}$ was measured heart rate rose significantly $(p<0.05)$. Cardenas and Vidaurris found similar changes, including a significant increase in $\max \mathrm{dp} / \mathrm{dt}(\mathrm{p}<0.05)$ and heart rate $(p<0.01)$ in seven patients. This study 5 was, however, biased in favour of a positive change by comparing the basal values with the peak effect for each index measured (not necessarily at the same moment). In both these studies ${ }^{35}$ at least part of the increase in $\max d p / d t$ is the result of the increase in heart rate. In neither study was an attempt made to demonstrate a true pharmacological effect of amrinone on the index of contractility chosen by constructing a dose response curve.

We therefore investigated the effect of amrinone on a number of indices of contractility as well as basic haemodynamics. We chose total doses of 1.5 and 3.5 
$\mathrm{mg} / \mathrm{kg}$ intravenous amrinone, being near the lower and upper limits of bolus doses used by previous workers. $3-5$ We arbitrarily chose to make our haemodynamic measurements seven minutes after the bolus injection, since in a number of models the peak haemodynamic changes occur two to 10 minutes after amrinone administration $^{1}$ and because this interval had been used by other workers. ${ }^{3}$ The use of a fixed interval prevents introduction of a bias by comparing peak changes.

Changes in the basic haemodynamics of our patients were similar to those seen by other workers. ${ }^{3-5} \mathrm{We}$ found beneficial changes in cardiac index and left ventricular filling pressures in our patients. We, in addition, found a significant reduction in mean arterial pressure, which was pronounced in some patients. In our patients, heart rate increased on amrinone which would tend to raise max dp/dt while both preload and blood pressure fell, tending to reduce $\max \mathrm{dp} / \mathrm{dt}$. The overall change in $\max \mathrm{dp} / \mathrm{dt}$ with amrinone would depend on the relative effect of each of these as well as any inotropic effect of the drug.

The reason for our inability to demonstrate a change in max dp/dt while such a change was shown by others 35 with much smaller groups of patients is not obvious, though the $27 \%$ increase in heart rate and use of peak effect by Cardenas and Vidaurri 5 may account for some of the difference. Neither group of patients was entirely comparable to our own. Cardenas and Vidaurri studied five patients with coronary artery disease and three patients with idiopathic cardiomyopathy, symptomatic at grade III or IV of the NYHA classification. All were on diuretics, but digitalis had been withdrawn for 15 days. Benotti et al. ${ }^{3}$ studied three patients with idiopathic cardiomyopathy and the remaining patients had valvular heart disease. The left ventricular ejection fraction in these patients was on average better than in our own, though their symptomatic grade was apparently worse. Benotti's patients were all receiving digoxin and diuretics but, unlike five of our patients, none was receiving vasodilators. The pre-amrinone max $\mathrm{dp} / \mathrm{dt}$ measurement in our patients was, however, only slightly worse than in the other two studies. It was not necessarily the patients with the lowest control max $\mathrm{dp} / \mathrm{dt}$ who showed the least rise after amrinone. Certainly cardiac index improved in patients who showed little or no change in $\max \mathrm{dp} / \mathrm{dt}$. Our work does not support the suggestion of others ${ }^{35}$ that administration of theidrug produces an increase in $\max \mathrm{dp} / \mathrm{dt}$.

In contrast to $\max \mathrm{dp} / \mathrm{dt},\left(\frac{\max d p / d t}{\mathrm{P}}\right)$ and $\max$ $\left(\frac{\mathrm{dp} / \mathrm{dt}}{\mathrm{P}}\right)$ are unaffected or affected very little by changes in preload and afterload. 7 15 The absence of a rise in these indices in the presence of an increase in heart rate is suggestive of an absence of a positive inotropic effect. KVmax calculated from developed left ventricular pressure is independent of afterload and relatively less dependent on preload than $\max \mathrm{dp} / \mathrm{dt}$. It appears to be the best pressure-derived measure of ventricular contractility developed thus far, as well as being the index most solidly founded on the more fundamental aspects of muscle fibre physiology.$^{8}$ No significant change in $\mathrm{KV} \max$ occurred after amrinone administration (and this remained true when the four patients with coronary artery disease were excluded). The ratio LVESP/LVESV is in fact the only index of contractility which can be considered to be truly independent of load 10 and it also remained unaltered after amrinone. These results suggest that the acute haemodynamic changes seen in our patients after intravenous amrinone are the result of its powerful vasodilator properties and not of any significant positive inotropic property.

Our inability to demonstrate a change in any index of contractility in our patients after amrinone may be because of one of three possibilities:

(1) These indices may be inadequate to detect positive inotropic changes in this class of patients, especially in the presence of concomitant vasodilatation.

(2) Patients with severe left ventricular impairment may be unable to produce a positive inotropic response to any intervention.

(3) Amrinone does not have positive inotropic properties in this class of patients in the doses used.

Further studies are currently being undertaken to distinguish between these possibilities.

Whether or not amrinone has positive inotropic properties in patients with congestive cardiac failure, it is clearly a very powerful vasodilator. As with other vasodilators there is a danger of large doses of the drug reducing preload excessively and lowering cardiac output, as we saw with two of our patients. This was a serious problem with one patient who had a restrictive cardiomyopathy caused by amyloidosis, who required very high filling pressures to maintain an adequate cardiac output. Intravenous administration of the drug should therefore be performed with care.

\section{References}

1 Alousi AA, Farah AE, Lesher GY, Opalka CJ Jr. Cardiotonic activity of amrinone-Win 40680 [5-Amino-3,4'bipyridin-6(1H)-one]. Circ Res 1979; 45: 666-77.

2 Alousi A, Helstosky A. Amrinone: a positive inotropic agent with direct vasodilatory activity in the canine isolated perfused hind limb preparation (abstract). Fed Proc 1980; 39: 855.

3 Benotti JR, Grossman W, Braunwald E, Davolos DD, Alousi AA. Hemodynamic assessment of amrinone: a new inotropic agent. $N$ Engl f Med 1978; 299: 1373-7.

4 LeJemtel TH, Keung E, Sonnenblick EH, et al. 
Amrinone: a new non-glycosidic, non-adrenergic cardiotonic agent effective in the treatment of intractable myocardial failure in man. Circulation 1979; 59: 1098104.

5 Cardenas LM, Vidaurri DA. Estudio de los efectos hemodinámicos de diferentes dosis de un nuevo inotrópico: la amrinona. Arch Inst Cardiol Mex 1979; 49: 961-8.

6 Reeves TJ, Hefner LL, Jones WB, Coghlan C, Prieto G, Carroll $\mathrm{J}$. The hemodynamic determinants of the rate of change in pressure in the left ventricle during isometric contraction. Am Heart F 1960; 60: 745-61.

7 Veragut UP, Krayenbühl HP. Estimation and quantification of myocardial contractility in the closed-chest dog. Cardiologia 1965; 47: 96-112.

8 Yang SS, Bentivoglio LG, Maranhão V, Goldberg H. From cardiac catheterization data to hemodymamic parameters. 2nd ed. Philadelphia: F A Davis, 1978: 233-358.

9 Kolettis M, Jenkins BS, Webb-Peploe MM. Assessment of left ventricular function by indices derived from aortic flow velocity. Br Heart $\mathcal{F}$ 1976; 38: 18-31.

10 Merillon JP, Motte G, Aumont MC, Prasquier R, Gourgon R. Study of left ventricular pressure-volume relations during nitroprusside infusion in human subjects without coronary artery disease. Br Heart $\mathcal{f}$ 1979; 41: 325-30.
11 Brooksby IAB, Swanton RH, Jenkins BS, Webb-Peploe $M M$. Long sheath technique for introduction of catheter tip manometer or endomyocardial bioptome into left or right heart. Br Heart f 1974; 36: 908-12.

12 Greene DG, Carlisle R, Grant C, Bunnell IL. Estimation of left ventricular volume by one-plane cineangiography. Circulation 1967; 35: 61-9.

13 Mason DT. Usefulness and limitations of the rate of rise of intraventricular pressure $(\mathrm{dp} / \mathrm{dt})$ in the evaluation of myocardial contractility in man. Am f Cardiol 1969; 23: 516-27.

14 Furnival CM, Linden RJ, Snow HM. Inotropic changes in the left ventricle: the effect of changes in heart rate, aortic pressure and end-diastolic pressure. $\mathcal{f}$ Physiol (Lond) 1970; 211: 359-87.

15 Mason DT, Sonnenblick EH, Covell JW, Ross J Jr, Braunwald E. Assessment of myocardial contractility in man: relationship between the rate of pressure rise and developed pressure throughout isometric left ventricular contraction (P) (abstract). . Circulation 1967; 36, suppl 2: 183-4.

Requests for reprints to Dr P T Wilmshurst, Department of Cardiology, St Thomas's Hospital, London SE1 7EH. 